\title{
Neurotoxicity from prenatal and postnatal exposure to methylmercury
}

\section{Citation}

Grandjean, Philippe, Pal Weihe, Frodi Debes, Anna L. Choi, and Esben Budtz-Jørgensen. 2014. "Neurotoxicity from Prenatal and Postnatal Exposure to Methylmercury." Neurotoxicology and Teratology 43 (May): 39-44. doi:10.1016/j.ntt.2014.03.004.

\section{Published Version}

doi:10.1016/j.ntt.2014.03.004

\section{Permanent link}

http://nrs.harvard.edu/urn-3:HUL.InstRepos:34767892

\section{Terms of Use}

This article was downloaded from Harvard University's DASH repository, and is made available under the terms and conditions applicable to Other Posted Material, as set forth at http:// nrs.harvard.edu/urn-3:HUL.InstRepos:dash.current.terms-of-use\#LAA

\section{Share Your Story}

The Harvard community has made this article openly available.

Please share how this access benefits you. Submit a story.

\section{Accessibility}




\title{
Effect of hemoglobin adjustment on the precision of mercury concentrations in maternal and cord blood
}

\author{
Byung-Mi Kim ${ }^{a, b}$, Anna L. Choi ${ }^{a}$, Eun-Hee Ha ${ }^{b}$, Lise Pedersen ${ }^{c}$, Flemming Nielsen ${ }^{d}$, Pal \\ Weihe $^{\mathrm{e}}$, Yun-Chul Hong ${ }^{f}$, Esben Budtz-Jørgensen ${ }^{g}$, and Philippe Grandjean ${ }^{\mathrm{a}, \mathrm{d}}{ }^{*}$
}

aDepartment of Environmental Health, Harvard School of Public Health, Boston, MA 02115, USA bDepartment of Preventive Medicine, School of Medicine, Ewha Medical Research Center, Ewha Womans University, Seoul, Korea 'Department of Clinical Chemistry \& Pharmacology, Odense University Hospital, Odense, Denmark Institute of Public Health, University of Southern Denmark, Odense, Denmark ${ }^{e}$ Faroese Hospital System, Torshavn, Faroe Islands ${ }^{\mathrm{f} D e p a r t m e n t}$ of Preventive Medicine, Seoul National University College of Medicine, Seoul, Korea 9Department of Biostatistics, University of Copenhagen, Copenhagen, Denmark

\begin{abstract}
The cord-blood mercury concentration is usually considered the best biomarker in regard to developmental methylmercury neurotoxicity. However, the mercury concentration may be affected by the binding of methylmercury to hemoglobin and perhaps also selenium. As cordblood mercury analyses appear to be less precise than suggested by laboratory quality data, we studied the interrelationships of mercury concentrations with hemoglobin in paired maternal and cord blood samples from a Faroese birth cohort $(\mathrm{N}=514)$ and the Mothers and Children's Environmental Health study in Korea $(\mathrm{n}=797)$. Linear regression and structural equation model (SEM) analyses were used to ascertain interrelationships between the exposure biomarkers and the possible impact of hemoglobin as well as selenium. Both methods showed a significant dependence of the cord-blood concentration on hemoglobin, also after adjustment for other exposure biomarkers. In the SEM, the cord blood measurement was a less imprecise indicator of the latent methylmercury exposure variable than other exposure biomarkers available, and the maternal hair concentration had the largest imprecision. Adjustment of mercury concentrations both in maternal and cord blood for hemoglobin improved their precision, while no significant effect of the selenium concentration in maternal blood was found. Adjustment of blood-mercury concentrations for hemoglobin is therefore recommended.
\end{abstract}

\footnotetext{
(c) 2014 Elsevier Inc. All rights reserved.

"Corresponding author: Dr. P. Grandjean, HSPH-EOME, 401 Park Drive, Room 3E-110, Boston, MA 02215. Ph: 617-384-8907. Fax: 617-384-8994. pgrand@hsph.harvard.edu.

Publisher's Disclaimer: This is a PDF file of an unedited manuscript that has been accepted for publication. As a service to our customers we are providing this early version of the manuscript. The manuscript will undergo copyediting, typesetting, and review of the resulting proof before it is published in its final citable form. Please note that during the production process errors may be discovered which could affect the content, and all legal disclaimers that apply to the journal pertain.
} 


\section{Keywords}

blood analysis; hemoglobin; methylmercury; prenatal exposure; selenium

\section{Introduction}

The cord-blood mercury $(\mathrm{Hg})$ concentration has been suggested as the best risk indicator in regard to methylmercury-associated developmental neurotoxicity (Grandjean et al., 2007).

However, as a biomarker of prenatal methylmercury exposure, the total $\mathrm{Hg}$ concentration in cord blood is associated with imprecision that exceeds the level suggested by laboratory quality assurance data (Grandjean et al., 2005; Grandjean et al., 2007). Some of this imprecision may be due to variable binding of methylmercury (MeHg) to erythrocytes, in which mercury binds to hemoglobin (Sakamoto et al., 2004). Previous studies have documented that $\mathrm{Hg}$ concentrations are higher in cord blood than in the corresponding maternal blood, likely due to the easy transfer of $\mathrm{MeHg}$ through the placenta (Kajiwara et al., 1996; Morrissette et al., 2004; Sakamoto et al., 2012), the greater affinity of MeHg to fetal hemoglobin (Hsu et al., 2007; Iyengar et al., 2001), and the higher hematocrit in newborns compared to their mothers (Stern et al., 2003). For this reason, standardization of the blood-Hg concentration to the one in erythrocytes has been recommended (Sakamoto et al., 2004). Adjustment for the hemoglobin concentration would likely be even better, although the impact on the imprecision has not been determined so far.

Another factor of possible relevance is that selenium (Se) is thought to bind to $\mathrm{MeHg}$ (Harris et al., 2003), thus possibly affecting the toxicokinetics of the latter. Hence, Se status could conceivably interfere with the transplacental transfer of $\mathrm{MeHg}$ and thus the partition between mother and fetus. However, previous studies of $\mathrm{Se}-\mathrm{MeHg}$ interactions have mainly focused on impacts on $\mathrm{MeHg}$ toxicity under particular exposure regimens that may not reflect human exposures. The earliest experimental studies showed that Se reduced the acute toxicity of $\mathrm{MeHg}$ injected into rats, thus suggesting the notion that Se may form complexes with $\mathrm{MeHg}$ in the blood, thereby decreasing the bioavailability of both elements (Ganther et al., 1972). More recent research in rodents supports that antioxidant nutrients, including Se, in the diet may alter the reproductive and developmental toxicity associated with $\mathrm{MeHg}$ exposure (Beyrouty et al., 2006). As Se is known to co-exist with $\mathrm{MeHg}$ in fish and sea mammals (Burger et al., 2007a; Burger et al., 2007b; Cabanero et al., 2005; Kaneko et al., 2007), a potential toxicokinetic interaction may occur in regard to transplacental transfer of $\mathrm{MeHg}$ from maternal seafood diets. Although human evidence on this possibility is not available, we considered Se as a covariate.

Imprecision of the exposure parameter is a crucial concern, because the exposure parameter in routine statistical calculations is usually treated as an independent variable without error (Grandjean and Budtz-Jørgensen, 2007). However, all biomarkers are subject to imprecision, and non-differential errors tend to bias the dose-response relationship toward the null (Fuller, 1987). To take into account the imprecision, a useful approach is to employ a structural equation model, where confounders and effect variables are included (BudtzJørgensen et al., 2002; Grandjean et al., 2007). In a Faroese birth cohort, the average total imprecision (expressed as the coefficient of variation) for the cord-blood $\mathrm{Hg}$ concentration 
was found to be about 25\% (Grandjean et al., 2005; Grandjean et al., 2007), a magnitude large enough to bias apparent dose-response relationships. The imprecision for hair $\mathrm{Hg}$ measurements is much greater. As only a very small part of such imprecision can be ascribed to laboratory variability, identification of other error sources is important.

Therefore, we assessed exposure biomarker imprecision and the impact of adjustment for hemoglobin and Se. We utilized data from birth cohort studies in the Faroe Islands and in Korea (Mothers and Children's Environmental Health, MOCEH).

\section{Materials and methods}

\subsection{Subjects}

A cohort of 514 singleton births was assembled at the National Hospital in the Faroe Islands during a 20-month period in 2007-2009. This North Atlantic population is of mainly Scandinavian origin, relatively uniform, and is covered by a modern health care service. The Faroese are of particular interest in environmental epidemiology, as pilot whale is among the traditional food items eaten as part of their marine diet. Pods of this small whale species are occasionally caught and the meat and blubber are shared locally. Because of the high $\mathrm{MeHg}$ concentration in the meat (Julshamn et al., 1987), the Faroese have a high average exposure to this contaminant and a wide range of exposure levels that depend on whale availability (Budtz-Jørgensen et al., 2004; Grandjean et al., 1992). At parturition, we obtained whole blood from the cord immediately after clamping. Maternal blood and hair was obtained approximately two weeks after parturition, when the mother brought the infant in for a scheduled health check-up. Cord blood and maternal blood were analyzed for total $\mathrm{Hg}$ and hemoglobin, while the maternal blood was also analyzed for Se. Complete samples sets were available from 514 subjects.

The MOCEH study was carried out in Korea to determine the effects of maternal environmental exposure on fetal and postnatal growth and development. All pregnant women living in the targeted study site (i.e., Seoul, Cheonan, and Ulsan), who were in their first trimester of pregnancy at the time of screening, were eligible. The maternal blood samples were obtained during late pregnancy (28-42 gestational weeks). The recruitment period in the MOCEH study was from 2006 to 2008 for the hospitals and clinics. A total of 921 women were eligible, and 124 women were not included due to exclusions or missing values in major variables. The study subjects were restricted to those for whom the maternal and cord blood Hg levels were assessed. Overall, 797 participants were eligible for this study.

\subsection{Subjects and biomarker assessment}

The Faroese blood samples were analyzed for total $\mathrm{Hg}$ by cold-vapor atomic absorption spectrometry on a Direct Mercury Analyzer DMA-80 (Milestone, Italy). Maternal hair-Hg was determined as previously described (Dalgard et al., 1994) by flow injection cold-vapor technique (FIMS-400 and AS-90; PerkinElmer, Wellesley, MA, USA). Quality assurance data showed imprecision levels below 5\% in agreement with previous studies (Grandjean et al., 2005; Grandjean et al., 2007). Selenium in blood was measured by Zeeman atomic furnace absorption spectrometry using an AA800 Zeeman Atomic Absorption 
Spectrophotometer fitted with THGA endcapped L'vov type graphite tubes, an EDL Selenium lamp current $280 \mathrm{~mA}$, and autosampler AS90 (all from Perkin Elmer). In regard to imprecision, the relative standard deviation was $3.5 \%$ for within-run repeatability and $5.2 \%$ between runs. Hemoglobin was determined by spectrometry on a Cobas Mira analyzer. Total hemoglobin was determined in $50 \mu \mathrm{L}$ whole blood by Drabkin's cyanomethemoglobin method on a Cobas Mira S analyser (Roche, Basel, Switzerland) using a $9.3 \mathrm{mmol} / \mathrm{L}$ hemoglobin standard from Cypress Diagnostics (Langdorp, Belgium) for calibration.

Mercury exposure biomarkers in Korea have been previously described (Kim et al., 2011). The analytical method for total Hg was similar (DMA-80, Milestone, Italy) with standard quality control procedures. The coefficient of variation (CV) of the $\mathrm{Hg}$ concentration between runs and within each run was 3.0\% and $2.5 \%$, respectively. Hemoglobin concentrations in MOCEH samples were analyzed using sodium lauryl sulfate (SLS)hemoglobin (Sysmex XE 2100D, CA, USA).

\subsection{Statistical analysis}

Following descriptive analyses, logarithmic transformations were used for the mercury biomarkers due to skewed distributions, and geometric means were calculated. Interrelationships between the transformed exposure biomarkers were determined by Pearson's correlation coefficients.

The dependence of the cord blood $\mathrm{Hg}$ concentration on hemoglobin and Se was first assessed in two regression models. In both models the cord blood $\mathrm{Hg}$ concentration was the dependent variable while hemoglobin and Se were independent variables. As an additional covariate, Model A included the maternal Hg blood concentration while Model B instead used the maternal hair concentration for comparison purposes. The adjustment for another $\mathrm{MeHg}$ exposure biomarker is critical as it will remove a possible association between selenium and level of prenatal mercury exposure. The analysis will then reveal whether the cord blood mercury concentration depends on selenium in children with the same exposure level. Regression coefficients are expressed as change of the $\mathrm{Hg}$ concentration in cord blood associated with a doubling of other exposure biomarkers. We report two-sided $p$-values.

As a supplement, a structural equation model was developed for the exposure biomarkers (Budtz-Jørgensen et al., 2002). In these models, observed variables are assumed to depend on common latent variables which may in turn depend on covariates. Thus, each of the exposure markers $(\mathrm{M}-\mathrm{Hg})$ was assumed to be manifestations of the true (unobserved) exposure $(H g)$ and a random error $\left(\varepsilon_{\mathrm{m}}\right)$ :

$$
\log (M-H g)=\alpha_{\mathrm{m}}+\lambda_{\mathrm{m}} \log (H g)+\varepsilon_{\mathrm{m}},
$$

When a least three independent exposure markers are available, the model can be estimated. Here we chose to express the latent exposure on the scale of the cord blood concentration. This was done by fixing the factor loading $\left(\lambda_{m}\right)$ at 1 for the cord-blood concentrations. With this restriction, a one-unit increase in log-Hg will on average lead to a one-unit increase in $\log$ cord blood Hg. In these models, a scale for the latent variables is required, but this 
choice has no implications for the correlations between the markers and the latent variable or the size of the error standard deviation (Bollen, 1989; Sanchez et al., 2005). The imprecision of the exposure marker is then modelled in terms of the random error term, $\varepsilon_{\mathrm{m}}$, which is assumed to follow a normal distribution with mean of zero and a standard deviation $\left(\sigma_{\mathrm{m}}\right)$. When a natural $\log$ transformation is used, standard deviation of the error term is a mathematical approximation to the error coefficient of variation $(\mathrm{CV})$ of the untransformed concentrations (Budtz-Jørgensen et al., 2007).

Model 1 included only the three $\mathrm{Hg}$ concentrations (Fig. 2) while model 2 included the available information about hemoglobin $(\mathrm{Hb})$ and Se as covariates (Fig 3). Thus, the latent mercury exposure $(\mathrm{Hg})$ was allowed to depend linearly on all three variables. In addition, the cord blood $\mathrm{Hg}$ concentration was allowed to depend directly on the $\mathrm{Hb}$ in the cord blood and the Se level. Similar effects were included for the maternal blood concentration. These direct effects were incorporated by modifying the model equations to include selenium and $\mathrm{Hb}$ :

$$
\log (M-H g)=\alpha_{\mathrm{m}}+\lambda_{\mathrm{m}} \log (H g)+\beta_{\mathrm{mhb}} \log (\mathrm{Hb})+\beta_{\mathrm{mse}} \log \mathrm{Se}+\varepsilon_{\mathrm{m}}
$$

This equation is very similar to the regression models described above, but the SEM has the advantage of using all available information to estimate a true (latent) exposure level and it takes into consideration the imprecision of the variables. Parameters were estimated using the maximum likelihood method and the fit of the more complex Model 2 was assessed by the chi-square test comparing the expected the observed covariance matrix and by Root Mean Square Error of Approximation (RMSEA) (Kline, 2012). A model is considered to have a good fit if the chi-square test has a p-value above 5\% and RMSEA below 5\%.

\section{Results}

The geometric means of the $\mathrm{Hg}$ concentrations in cord blood averaged $50 \%$ higher than those of post-parturition maternal blood samples in the Faroes and closer to $70 \%$ higher than the Korean maternal blood collected during pregnancy. The interquartile range (IQR) and total range for the $\mathrm{Hg}$ concentrations reflected substantial variation, whereas the range of $\mathrm{Hb}$ and Se was much narrower (Table 1). Mercury in maternal blood correlated well with concentrations in maternal hair and in cord blood, but much less closely with Se in maternal blood (Fig 1).

Multiple regression models showed a positive effect of $\mathrm{Hb}$ on the cord blood concentration (Table 2). This effect was statistically significant after adjustment for maternal blood concentration (Model A) and the maternal hair concentration (Model B). The possible effect of Se was more uncertain. Thus, no effect of Se was apparent in Model A, but a significant positive effect was seen in model 2 when adjustment included only mercury in maternal hair. However, blood-Se was closely associated with maternal blood-Hg, and the regression coefficient for maternal blood-Hg was greater than that for maternal hair- $\mathrm{Hg}$ as predictors of cord blood $\mathrm{Hg}$. 
We then performed SEM analyses to further explore the interrelationships between the exposure biomarkers and a latent exposure variable based on the analyses available from the Faroes (Tables 3 and 4). The extended SEM (Fig. 3) showed a good fit to the data ( $p=0.32$ for difference between observed and predicted covariances, RMSEA $=0.016$ ). In agreement with the multiple regression analyses, this model showed a strong positive effect $(\mathrm{p}<0.001)$ of $\mathrm{Hb}$ on the cord blood- $\mathrm{Hg}$ concentration for fixed level of the latent exposure (Table 3). A similar effect was also seen for the maternal blood-Hg concentration. Selenium did not seem to affect the observed $\mathrm{Hg}$ concentrations, although it was strongly related to the latent mercury concentration $(\mathrm{p}<0.001)$ as an indication that higher $\mathrm{MeHg}$ exposures were associated with increased Se intakes.

In the simple structural equation model without information about $\mathrm{Se}$ and $\mathrm{Hb}$ (Fig. 2), the cord blood measurement was the most precise exposure marker, and the maternal blood measure was only slightly inferior, as reflected by the error CVs (Table 4, Model 1). As expected, the maternal hair concentration had the largest error component (Table 4). The extended SEM (Fig 3) showed the same ordering of the markers, but after adjustment for $\mathrm{Hb}$, the error $\mathrm{CV}$ for the cord blood concentration decreased from about $11 \%$ (Table 4 , Model 1) to about 3\% (Table 4, Model 2), which is similar to the analytical imprecision.

\section{Discussion}

An imprecise exposure assessment may complicate confounder adjustment and lead to an underestimation of dose-effect relationships (Budtz-Jørgensen et al., 2003; Carroll, 1998). Therefore, this problem may be exaggerated by potential confounders that are correlated with the exposure. In regression analyses, inclusion of such variables - when measured with better precision - may further add to the average bias toward the null hypothesis (BudtzJørgensen et al., 2003), even in cases where the potential confounder has no independent effect on the outcome. Thus, assessment of total exposure biomarker imprecision is an important issue to environmental epidemiology studies. However, the imprecision of exposure data in epidemiological studies is usually unknown (Grandjean et al., 2007) and is often ignored.

The present study examined the precision of the cord-blood $\mathrm{Hg}$ concentration while considering the impact of adjustment for blood covariates. Using standard regression techniques we have demonstrated a strong positive dependence of the cord blood-Hg concentration on the $\mathrm{Hb}$ level, also after adjustment for other mercury exposure biomarkers. Because three exposure parameters were available, a structural equation analysis could also be conducted. This analysis confirmed the regression results and showed in addition that the $\mathrm{Hg}$ concentration in cord blood is less imprecise than the concentrations in maternal hair and maternal blood, and that adjustment for $\mathrm{Hb}$ further improves the precision of this exposure biomarker. A higher $\mathrm{Hb}$ concentration (or hematocrit) is known to result in greater $\mathrm{MeHg}$ binding in whole blood and thus a higher $\mathrm{Hg}$ concentration in the blood sample. Accordingly, some researchers prefer to measure the $\mathrm{Hg}$ concentration in erythrocytes (Sakamoto et al., 2004), although this procedure may be more cumbersome than the analysis of whole blood for both mercury and hemoglobin. 
Hemoglobin concentrations in maternal blood are also of importance. In the present study, a lower hematocrit during pregnancy than two weeks after parturition is the likely explanation of the differences in blood $\mathrm{Hg}$ concentrations between the two study populations. Due to this difference, cord blood has a $\mathrm{Hg}$ concentration about $50 \%$ greater than the one in maternal blood two weeks after parturition and 70\% higher than first-trimester maternal blood.

While the total $\mathrm{Hg}$ concentrations includes both $\mathrm{MeHg}$ and inorganic $\mathrm{Hg}$ species in routine analyses, the $\mathrm{Hg}$ concentration in cord blood reflects mainly the methylated form, for which the placenta does not constitute a barrier (Kelman et al., 1982). Thus, speciation of $\mathrm{Hg}$ in cord blood is not needed. In contrast, $\mathrm{Hg}$ in maternal blood may not be a precise measure of fetal $\mathrm{MeHg}$ exposure due to the presence of inorganic mercury. Still, our results suggest that the imprecision of maternal blood $\mathrm{Hg}$ remains far better than the one for hair $\mathrm{Hg}$. It is also noteworthy that the loading factor for maternal blood $\mathrm{Hg}$ was higher in the Faroes study than in the Korean study. This result is probably due to the maternal blood in the Faroes being sampled much closer to parturition where the cord blood was obtained.

Available evidence suggests that the cord blood $\mathrm{Hg}$ concentration is the best risk indicator for MeHg neurotoxicity (Grandjean et al., 2002; National Research Council, 2000). Given the larger imprecision of the maternal hair $\mathrm{Hg}$ parameter and its known variation with hair type and hair color (Grandjean et al., 2002), this highly feasible and widely used exposure biomarker is less appropriate for prenatal MeHg exposure assessment. The present study shows that adjustment of blood-based biomarkers by the $\mathrm{Hb}$ concentration will further improve the precision of the $\mathrm{Hg}$ concentration in both maternal and cord blood. This adjustment may also provide better precision than in previous studies that rely on cord blood concentrations (Grandjean et al., 2002; Grandjean and Budtz-Jørgensen, 2007).

Among the limitations of this study, we did not analyze serum-Hg concentrations of maternal blood to obtain an indication of the amount of inorganic $\mathrm{Hg}$ species. Still, our results show that the imprecision based on whole-blood analysis only was only slightly greater than for cord blood. Also, we did not analyze Se in the MOCEH study. However, no effect of Se could be determined in the Faroes data, so this omission is probably inconsequential. The molar ratio between $\mathrm{Hg}$ and $\mathrm{Se}$ is relevant for possible interactions between the elements (Newland et al., 2006). The Faroese data show an average Se molar excess of about a 50-fold above $\mathrm{Hg}$ concentrations. This excess suggests that all Faroese children are Se sufficient and that $\mathrm{MeHg}$ toxicity is independent of any relative degree of $\mathrm{Se}$ sufficiency. Se in maternal blood showed a positive correlation with the maternal $\mathrm{Hg}$ concentration, which is consistent with other studies (Barany et al., 2003; Bates et al., 2006; Svensson et al., 1992), possibly because both substances originated, at least in part, from the same marine food sources (Karita et al., 2002; Svensson et al., 1995; Svensson et al., 1992). However, a positive correlation between $\mathrm{Hg}$ and $\mathrm{Se}$ in maternal blood does not necessarily imply that $\mathrm{Se}$ can moderate the toxicity of $\mathrm{MeHg}$ in humans. While $\mathrm{Hg}$ in cord blood was weakly associated with Se in maternal blood, the SEM revealed no statistically significant association between maternal Se and the cord blood $\mathrm{Hg}$. These findings imply that any protective effects of Se against MeHg toxicity are not manifested via impaired transport through the placenta. The present study therefore shows that any toxicokinetic interference 
by Se would have no important effect on the partition of $\mathrm{MeHg}$ between maternal and fetal circulations.

Recently, a Japanese study also found no significant positive correlation between $\mathrm{Hg}$ and $\mathrm{Se}$ concentrations in cord blood (Sakamoto et al., 2010). However, experimental studies examining $\mathrm{Hg}$ and $\mathrm{Se}$ exposure in relation to neurodevelopment have produced inconclusive evidence, especially at levels comparable to human exposures (Reed et al., 2006). A Faroese birth study failed to identify any protective effect of Se against MeHg neurotoxicity (Choi et al., 2008). Selenium therefore seems to be of marginal, if any, interest in regard to $\mathrm{MeHg}$ toxicity in populations that are Se sufficient.

The two cohort studies demonstrated that $\mathrm{Hg}$ concentrations in cord blood strongly depend on the $\mathrm{Hg}$ concentrations in maternal blood, but the regression coefficients (and their confidence intervals) for maternal blood differed between the Faroese birth cohort study and the MOCEH study. This difference may be due to the different times of maternal blood sampling in the two studies. In the Faroes cohort, the maternal blood was obtained two weeks after parturition, i.e., at a time when the blood volume had approached non-pregnant levels. In the Korean cohort, maternal blood was sampled during late pregnancy when the blood volume was expanded, thus leading to lower concentrations of both $\mathrm{Hb}$ and $\mathrm{Hg}$. While hemoglobin concentrations were taken into account, physiological differences in $\mathrm{MeHg}$ distribution in the body may have played a role as well. Also, the greater interval between paired sample collections in the Korea study may have increased the variability of relative $\mathrm{Hg}$ concentrations in the blood samples. In addition, the results may be affected by distinct racial/ethnic/cultural differences, as biases of the chemical analyses would seem unlikely. Also, Caucasian hair grows faster than Oriental hair, and the hair growth rate generally decreases with age (Lam, 2005). Such ethnically-related differences are likely independent of seafood consumption (Caldwell et al., 2009) but may affect the incorporation of $\mathrm{Hg}$ in hair.

A previous calculation of the total imprecision (Budtz-Jørgensen et al., 2003) suggested that the cord-blood $\mathrm{Hg}$ concentration had a total imprecision $\mathrm{CV}$ of about $25 \%$, while maternal hair had one almost twice as high. In this calculation, the frequency of whale meat consumption was used as the third parameter needed to calculate the latent exposure variable. Because the three variables are independent and reflect different aspects of dietary $\mathrm{MeHg}$ exposure during pregnancy, the $\mathrm{CV}$ of $25 \%$ is probably a good reflection of the total variability. The present study included the maternal blood $\mathrm{Hg}$, which constitutes the source of the $\mathrm{MeHg}$ that leads to a $\mathrm{Hg}$ concentration in the cord blood. The same applies to the hemoglobin in both blood samples, both of which likely depend on the maternal iron status. Thus, these measurements may not be fully independent, and the error variance of the latent variable may be underestimated for this reason. However, the error SD decreased from 0.11 to 0.03 after adjustment for hemoglobin in both maternal blood and cord blood in Faroese study. Selenium alone had only a negligible effect. Thus, although the variables may not be fully independent, the improvement in error CV achieved by hemoglobin adjustment would strongly support this way of expressing the blood $\mathrm{Hg}$ concentrations. Further, the imprecision of the hair-Hg remained much higher than for the blood-Hg concentrations. 
Due to imprecisions of exposure parameters, calculated associations will tend to be biased toward the null, and inclusion of covariates may add to the bias (Budtz-Jørgensen et al., 2003). Most studies on MeHg biomarker associations have applied standard regression equations (Akagi, 1998; Bjornberg et al., 2003; Haxton et al., 1979; Phelps et al., 1980; Sherlock et al., 1982; Turner et al., 1980). An important limitation is that this approach includes measurement error only in the dependent variable (Fuller, 1987). A structural equation model allows for measurement error in both variables, and may therefore be a more appropriate choice for estimation of the relation between the two biomarkers.

The findings of this study support the use of cord blood as the best available exposure biomarker for $\mathrm{MeHg}$, and its precision can be improved by adjustment for hemoglobin. $\mathrm{Hg}$ in maternal blood is also appropriate as a risk indicator after adjustment for hemoglobin, although the sampling time must be carefully considered. However, hair $\mathrm{Hg}$ concentrations are less precise and may result in bias toward the null. Although $\mathrm{Hg}$ and Se concentrations in maternal blood showed significant correlations, only a weak association was found between $\mathrm{Se}$ in maternal blood and $\mathrm{Hg}$ in cord blood, thus suggesting that any protective effects of Se against $\mathrm{MeHg}$ toxicity do not depend on toxicokinetic interference.

\section{Acknowledgments}

Funding sources: This study was supported by the U.S. National Institute of Environmental Health Sciences (ES09797 and ES012199) and the National Institute of Environmental Research and National Research Foundation of Korea, Republic of Korea. The birth cohort project in the Faroe Islands was approved by the Faroese ethical review committee and the Institutional Review Board at Harvard School of Public Health. The Mothers and Children's Environmental Health study in Korea was approved by the Institutional Review Board at EWHA Womans' University, Seoul, South Korea. In both studies, each mother provided written informed consent in accordance with the approved protocols.

We are grateful to Ranja Bjerring for conducting mercury analyses on Faroese samples and to the children and their mothers for participating in the two birth cohort studies.

\section{Abbreviations}

AAS

AGFI

AIC

CB-Hb

CB-Hg

CFI

CV

GFI

GM

$\mathrm{Hg}$

IQR
Atomic absorption spectrometry

Adjusted Goodness of Fit Index

Akaike information criterion

hemoglobin in cord blood

$\mathrm{Hg}$ in cord blood

Comparative fit index

Coefficient of variation

Goodness of fit index

Geometric means

Mercury

Interquartile range 


$\begin{array}{ll}\text { MB-Hb } & \text { Hemoglobin in maternal blood } \\ \text { MB-Hg } & \text { Hg in maternal blood } \\ \text { MB-Se } & \text { Selenium in maternal blood } \\ \text { MeHg } & \text { Methylmercury } \\ \text { MH-Hg } & \text { Hg in maternal hair } \\ \text { MOCEH } & \text { Mothers and Children's Environmental Health } \\ \text { Se } & \text { Selenium } \\ \text { SEM } & \text { Structural equation model } \\ \text { SLS } & \text { Sodium lauryl sulfate } \\ \text { TLI } & \text { Tucker-Lewis index }\end{array}$

\section{References}

Akagi H. Studies on Mercury Pollution in the Amazon, Brazil. Global Environ Res. 1998; 2:193-202.

Barany E, Bergdahl IA, Bratteby LE, Lundh T, Samuelson G, Skerfving S, et al. Mercury and selenium in whole blood and serum in relation to fish consumption and amalgam fillings in adolescents. J Trace Elem Med Biol. 2003; 17(3):165-170. [PubMed: 14968928]

Bates CJ, Prentice A, Birch MC, Delves HT, Sinclair KA. Blood indices of selenium and mercury, and their correlations with fish intake, in young people living in Britain. Br J Nutr. 2006; 96(3):523531. [PubMed: 16925858]

Beyrouty P, Chan HM. Co-consumption of selenium and vitamin E altered the reproductive and developmental toxicity of methylmercury in rats. Neurotoxicol Teratol. 2006; 28(1):49-58. [PubMed: 16427250]

Bjornberg KA, Vahter M, Petersson-Grawe K, Glynn A, Cnattingius S, Darnerud PO, et al. Methyl mercury and inorganic mercury in Swedish pregnant women and in cord blood: influence of fish consumption. Environ Health Perspect. 2003; 111(4):637-641. [PubMed: 12676628]

Bollen, KA. Structural equations with latent variables. John Wiley; New York: 1989.

Budtz-Jørgensen E, Grandjean P, Jorgensen PJ, Weihe P, Keiding N. Association between mercury concentrations in blood and hair in methylmercury-exposed subjects at different ages. Environ Res. 2004; 95(3):385-393. [PubMed: 15220072]

Budtz-Jørgensen E, Grandjean P, Weihe P. Separation of risks and benefits of seafood intake. Environ Health Perspect. 2007; 115(3):323-327. [PubMed: 17431478]

Budtz-Jørgensen E, Keiding N, Grandjean P, Weihe P. Estimation of health effects of prenatal methylmercury exposure using structural equation models. Environ Health. 2002; 1(1):2. [PubMed: 12513702]

Budtz-Jørgensen E, Keiding N, Grandjean P, Weihe P, White RF. Consequences of exposure measurement error for confounder identification in environmental epidemiology. Stat Med. 2003; 22(19):3089-3100. [PubMed: 12973789]

Burger J, Gochfeld M. Risk to consumers from mercury in Pacific cod (Gadus macrocephalus) from the Aleutians: fish age and size effects. Environ Res. 2007a; 105(2):276-284. [PubMed: 17599825]

Burger J, Gochfeld M, Shukla T, Jeitner C, Burke S, Donio M, et al. Heavy metals in Pacific cod (Gadus macrocephalus) from the Aleutians: location, age, size, and risk. J Toxicol Environ Health A. 2007b; 70(22):1897-1911. [PubMed: 17966061] 
Cabanero AI, Carvalho C, Madrid Y, Batoreu C, Camara C. Quantification and speciation of mercury and selenium in fish samples of high consumption in Spain and Portugal. Biol Trace Elem Res. 2005; 103(1):17-35. [PubMed: 15695845]

Caldwell KL, Mortensen ME, Jones RL, Caudill SP, Osterloh JD. Total blood mercury concentrations in the U.S. population: 1999-2006. Int J Hyg Environ Health. 2009; 212(6):588-598. [PubMed: 19481974]

Carroll, RJ. Measurement error in epidemiologic studies. In: Armitage, P.; Colton, T., editors. Encyclopedia of biostatistics. Wiley; Chichester: 1998. p. 2491-2519.

Choi AL, Budtz-Jørgensen E, Jørgensen PJ, Steuerwald U, Debes F, Weihe P, et al. Selenium as a potential protective factor against mercury developmental neurotoxicity. Environ Res. 2008; 107(1):45-52. [PubMed: 17854796]

Dalgard C, Grandjean P, Jørgensen PJ, Weihe P. Mercury in the Umbilical Cord: Implications for Risk Assessment for Minamata Disease. Environ Health Perspect. 1994; 102(6-7):548-550. [PubMed: 9679113]

Fuller, WA. Measurement error models. Wiley; New York: 1987.

Ganther HE, Goudie C, Sunde ML, Kopecky MJ, Wagner P. Selenium: relation to decreased toxicity of methylmercury added to diets containing tuna. Science. 1972; 175(26):1122-1124. [PubMed: 5062150]

Grandjean P, Budtz-Jørgensen E, Jørgensen PJ, Weihe P. Umbilical cord mercury concentration as biomarker of prenatal exposure to methylmercury. Environ Health Perspect. 2005; 113(7):905908. [PubMed: 16002381]

Grandjean P, Budtz-Jørgensen E. Total imprecision of exposure biomarkers: implications for calculating exposure limits. Am J Ind Med. 2007; 50(10):712-719. [PubMed: 17492658]

Grandjean, P.; Jørgensen, PJ.; Weihe, P. Validity of mercury exposure biomarkers. In: Wilson, SH.; Suk, WA., editors. Biomarkers of Environmentally Associated Disease. CRC Press/Lewis Publishers; Boca Raton: 2002. p. 235-247.

Grandjean P, Weihe P, Jørgensen PJ, Clarkson T, Cernichiari E, Videro T. Impact of maternal seafood diet on fetal exposure to mercury, selenium, and lead. Arch Environ Health. 1992; 47(3):185-195. [PubMed: 1596101]

Harris HH, Pickering IJ, George GN. The chemical form of mercury in fish. Science. 2003; 301(5637): 1203. [PubMed: 12947190]

Haxton J, Lindsay DG, Hislop JS, Salmon L, Dixon EJ, Evans WH, et al. Duplicate diet study on fishing communities in the United Kingdom: mercury exposure in a "critical group". Environ Res. 1979; 18(2):351-368. [PubMed: 510256]

Hsu C, Liu P, Chien L, Chou S, Han B. Mercury concentration and fish consumption in Taiwanese pregnant women. BJOG. 2007; 114:81-85. [PubMed: 17081179]

Iyengar GV, Rapp A. Human placenta as a 'dual' biomarker for monitoring fetal and maternal environment with special reference to potentially toxic trace elements. Part 1: physiology, function and sampling of placenta for elemental characterisation. Sci Total Environ. 2001; 280(1-3):195206. [PubMed: 11763267]

Julshamn K, Andersen A, Ringdal O, Morkore J. Trace elements intake in the Faroe Islands. I. Element levels in edible parts of pilot whales (Globicephalus meleanus). Sci Total Environ. 1987; 65:53-62. [PubMed: 3685941]

Kajiwara Y, Yasutake A, Adachi T, Hirayama K. Methylmercury transport across the placenta via neutral amino acid carrier. Arch Toxicol. 1996; 70(5):310-314. [PubMed: 8852703]

Kaneko JJ, Ralston NV. Selenium and mercury in pelagic fish in the central north pacific near Hawaii. Biol Trace Elem Res. 2007; 119(3):242-254. [PubMed: 17916947]

Karita K, Suzuki T. Fish eating and variations in selenium and mercury levels in plasma and erythrocytes in free-living healthy Japanese men. Biol Trace Elem Res. 2002; 90(1-3):71-81. [PubMed: 12666827]

Kelman BJ, Walter BK, Sasser LB. Fetal distribution of mercury following introduction of methylmercury into porcine maternal circulation. J Toxicol Environ Health. 1982; 10(2):191-200. [PubMed: 7143475] 
Kim BM, Lee BE, Hong YC, Park H, Ha M, Kim YJ, et al. Mercury levels in maternal and cord blood and attained weight through the 24 months of life. Sci Total Environ. 2011; 410-411:26-33.

Kline, RB. Principles and Practice of Structural Equation Modeling. 3. Guilford; New York: 2012.

Lam SM. Aesthetic facial surgery for the asian male. Facial Plast Surg. 2005; 21(4):317-323. [PubMed: 16575710]

Morrissette J, Takser L, St-Amour G, Smargiassi A, Lafond J, Mergler D. Temporal variation of blood and hair mercury levels in pregnancy in relation to fish consumption history in a population living along the St. Lawrence River. Environ Res. 2004; 95(3):363-374. [PubMed: 15220070]

National Research Council. Toxicological effects of methylmercury. National Academy Press; Washington, DC: 2000.

Newland MC, Reed MN, LeBlanc A, Donlin WD. Brain and blood mercury and selenium after chronic and developmental exposure to methylmercury. Neurotoxicology. 2006; 27(5):710-720. [PubMed: 16824603]

Phelps RW, Clarkson TW, Kershaw TG, Wheatley B. Interrelationships of blood and hair mercury concentrations in a North American population exposed to methylmercury. Arch Environ Health. 1980; 35(3):161-168. [PubMed: 7189997]

Reed MN, Paletz EM, Newland MC. Gestational exposure to methylmercury and selenium: effects on a spatial discrimination reversal in adulthood. Neurotoxicology. 2006; 27(5):721-732. [PubMed: 16759706]

Sakamoto M, Chan HM, Domingo JL, Kawakami S, Murata K. Mercury and docosahexaenoic acid levels in maternal and cord blood in relation to segmental maternal hair mercury concentrations at parturition. Environ Int. 2012; 44:112-117. [PubMed: 22425897]

Sakamoto M, Kubota M, Liu XJ, Murata K, Nakai K, Satoh H. Maternal and fetal mercury and n-3 polyunsaturated fatty acids as a risk and benefit of fish consumption to fetus. Environ Sci Technol. 2004; 38(14):3860-3863. [PubMed: 15298193]

Sakamoto M, Murata K, Kubota M, Nakai K, Satoh H. Mercury and heavy metal profiles of maternal and umbilical cord RBCs in Japanese population. Ecotoxicol Environ Saf. 2010; 73(1):1-6. [PubMed: 19819550]

Sanchez BN, Budtz-Jørgensen E, Ryan L, Hu H. Structural equation models: a review with applications to environmental epidemiology. J Am Stat Assoc. 2005; 100(472):1443-1455.

Sherlock JC, Lindsay DG, Hislop JE, Evans WH, Collier TR. Duplication diet study on mercury intake by fish consumers in the United Kingdom. Arch Environ Health. 1982; 37(5):271-278. [PubMed: 7138076]

Stern AH, Smith AE. An assessment of the cord blood:maternal blood methylmercury ratio: implications for risk assessment. Environ Health Perspect. 2003; 111(12):1465-1470. [PubMed: 12948885]

Svensson BG, Nilsson A, Jonsson E, Schutz A, Akesson B, Hagmar L. Fish consumption and exposure to persistent organochlorine compounds, mercury, selenium and methylamines among Swedish fishermen. Scand J Work Environ Health. 1995; 21(2):96-105. [PubMed: 7618064]

Svensson BG, Schutz A, Nilsson A, Akesson I, Akesson B, Skerfving S. Fish as a source of exposure to mercury and selenium. Sci Total Environ. 1992; 126(1-2):61-74. [PubMed: 1439752]

Turner MD, Marsh DO, Smith JC, Inglis JB, Clarkson TW, Rubio CE, et al. Methylmercury in populations eating large quantities of marine fish. Arch Environ Health. 1980; 35(6):367-378. [PubMed: 7192967]

Wei G, Bhushan B, Torgerson PM. Nanomechanical characterization of human hair using nanoindentation and SEM. Ultramicroscopy. 2005; 105(1-4):248-266. [PubMed: 16111814] 


\section{Highlights}

- The cord-blood mercury concentration reflects risk of developmental neurotoxicity

- This concentration may be imprecise due to binding to hemoglobin

- Structural equations were used to compare mercury in maternal and cord blood samples

- Adjustment of mercury concentrations for hemoglobin improved their precision 


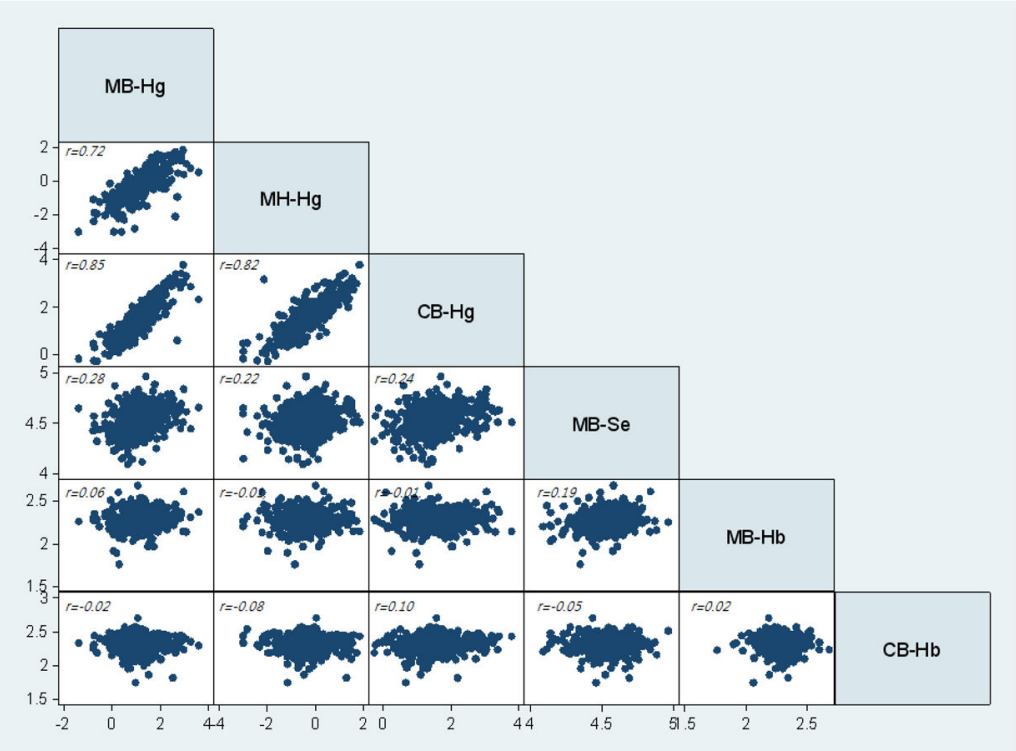

Figure 1.

Correlations between logarithmic transformations of biomarkers in the Faroese birth cohort. ${ }^{\mathrm{a}} \mathrm{MB}-\mathrm{Hg}, \mathrm{Hg}$ in maternal blood; $\mathrm{MH}-\mathrm{Hg}, \mathrm{Hg}$ in maternal hair; $\mathrm{Hg}$, latent variable; $\mathrm{CB}-\mathrm{Hg}$, MB-Se, Selenium in maternal blood; MB-Hb, Hemoglobin in maternal blood; $\mathrm{Hg}$ in cord blood; CB-Hb, hemoglobin in cord blood - 


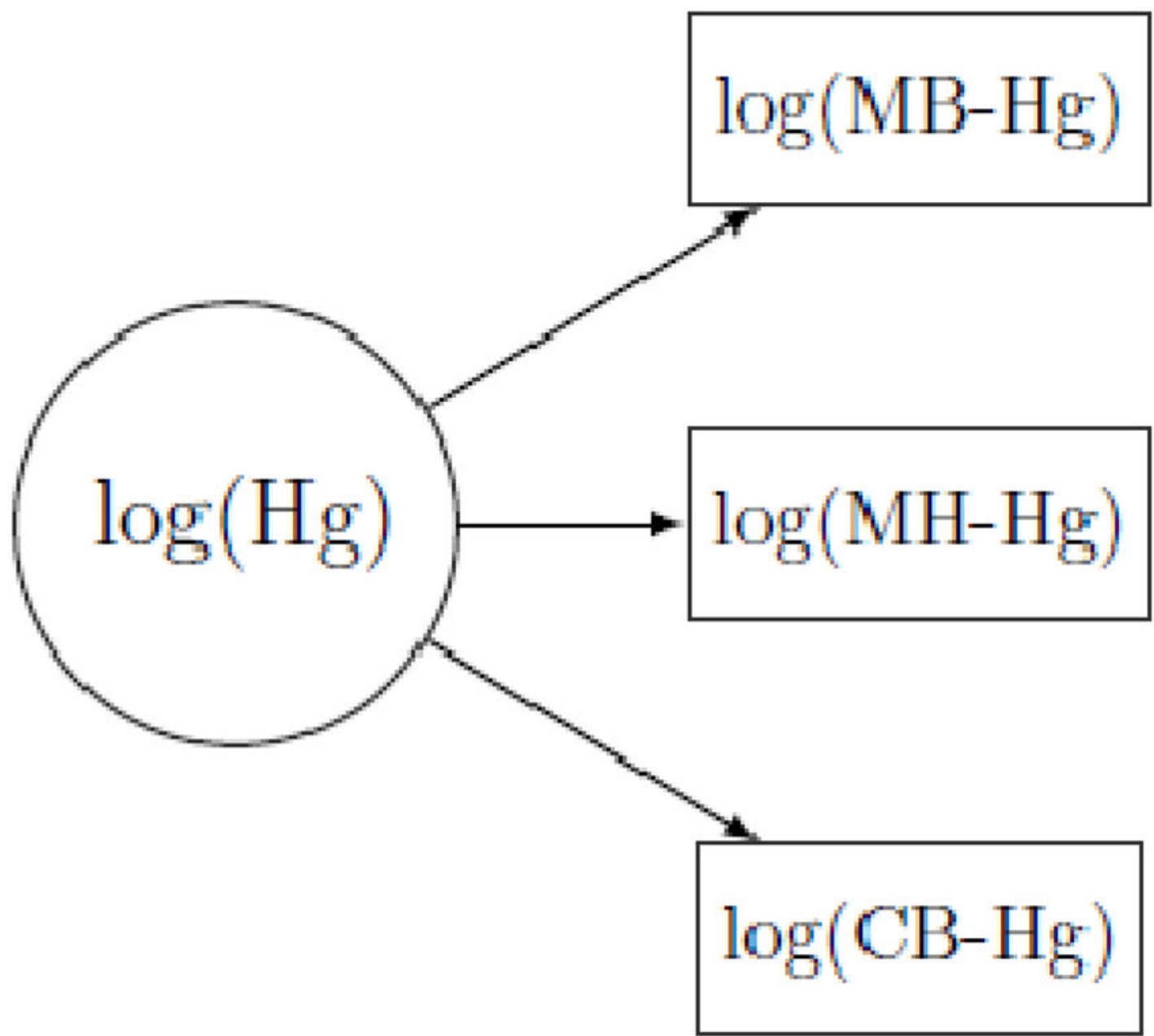

Fig. 2.

Structural equation model of latent methylmercury exposure $(\mathrm{Hg})$, as indicated by mercury concentrations in maternal blood (MB-Hg), maternal hair (MH-Hg), and cord blood (CB$\mathrm{Hg}$ ), all of which are log transformed. 


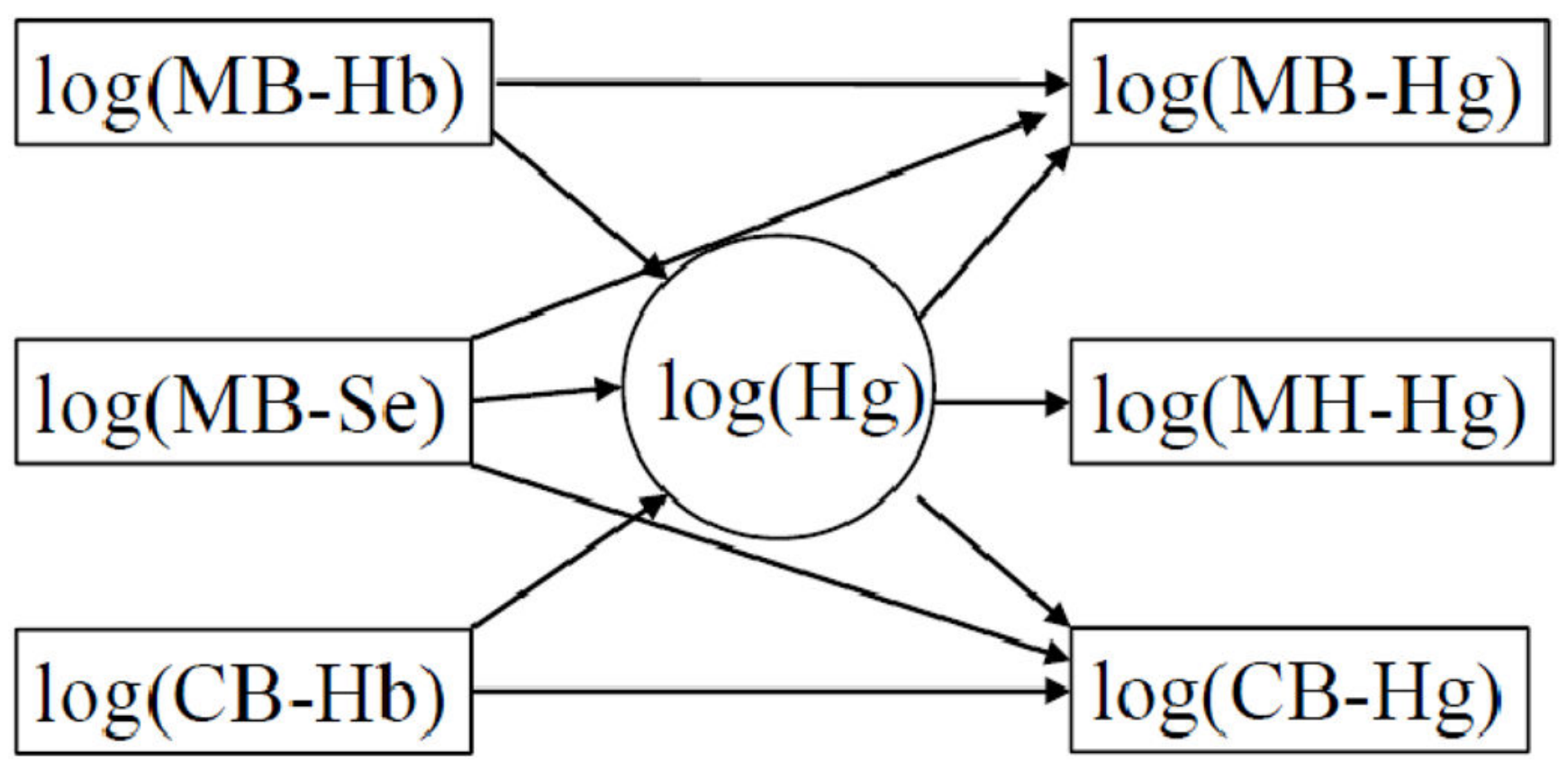

Fig. 3.

Extended structural equation model that allows the hemoglobin concentrations in maternal and cord blood to affect the mercury concentrations in the same media while also allowing the maternal selenium concentration to affect the blood-mercury concentrations. 


\section{Table 1}

Distribution summaries of mercury, selenium and hemoglobin. ${ }^{a}$

\begin{tabular}{lcccc}
\hline Biomarkers & N & Geometric mean $^{a}$ & Interquartile range & Total range \\
\hline Faroese birth cohort study & & & & \\
$\quad$ Maternal blood $\mathrm{Hg}(\mu \mathrm{g} / \mathrm{L})$ & 499 & 15.30 & $10.4-21.15$ & $1.25-188.1$ \\
Cord blood $\mathrm{Hg}(\mu \mathrm{g} / \mathrm{L})$ & 490 & 22.95 & $15.1-33.40$ & $3.85-222.4$ \\
Maternal hair $\mathrm{Hg}(\mu \mathrm{g} / \mathrm{g})$ & 504 & 0.71 & $0.44-1.10$ & $0.05-6.27$ \\
Selenium $(\mu \mathrm{g} / \mathrm{L})$ & 496 & 1,132 & $1,025-1,235$ & $718-1,715$ \\
Maternal hemoglobin $(\mathrm{mmol} / \mathrm{L})$ & 498 & 9.73 & $9.14-10.40$ & $5.84-14.57$ \\
Infant hemoglobin $(\mathrm{mmol} / \mathrm{L})$ & 488 & 10.12 & $9.51-10.83$ & $5.74-14.95$ \\
MOCEH study & & & & \\
Maternal blood $\mathrm{Hg}(\mu \mathrm{g} / \mathrm{L})$ & 797 & 15.45 & $2.24-4.12$ & $0.40-92.30$ \\
Cord blood $\mathrm{Hg}(\mu \mathrm{g} / \mathrm{L})$ & 796 & 25.90 & $3.95-7.00$ & $0.23-24.10$ \\
Maternal hemoglobin $(\mathrm{mmol} / \mathrm{L})$ & 558 & 11.92 & $11.30-12.80$ & $6.10-17.70$ \\
\hline
\end{tabular}

${ }^{a}$ To convert into nmol/L, multiply results in $\mu \mathrm{g} / \mathrm{L}$ by 5 (mercury) and 12 (selenium). 


\section{Table 2}

Linear regression coefficients for increase (in percent) in the cord blood mercury concentration associated with a doubling of different exposure biomarkers in the Faroese birth cohort. ${ }^{a}$

\begin{tabular}{lcc}
\hline & \multicolumn{2}{c}{ Cord blood mercury $(\mu \mathrm{g} / \mathrm{L})$} \\
\cline { 2 - 3 } & Percent increase & $\mathbf{9 5 \%}$ CI \\
\hline Model A & & \\
\hline Maternal blood mercury $(\mu \mathrm{g} / \mathrm{L})$ & 82.7 & 76.6 to 89.0 \\
Maternal blood selenium $(\mu \mathrm{g} / \mathrm{L})$ & 1.26 & -14.1 to 19,4 \\
Cord blood hemoglobin $(\mathrm{mmol} / \mathrm{L})$ & 53.3 & 27.6 to 84.1 \\
\hline Model B & & \\
\hline Maternal hair mercury $(\mu \mathrm{g} / \mathrm{L})$ & & 58.4 to 68.3 \\
Maternal blood selenium $(\mu \mathrm{g} / \mathrm{L})$ & 63.2 & 5.5 to 49.1 \\
Cord blood hemoglobin $(\mathrm{mmol} / \mathrm{L})$ & 25.4 & 47.0 to 118.0 \\
\hline
\end{tabular}




\section{Table 3}

Structural equation coefficients for increase (in percent) in mercury marker concentration in the Faroese birth cohort associated with a doubling in selenium and hemoglobin concentrations after adjustment for latent true mercury concentration.

\begin{tabular}{lcc}
\hline Predictor & Percent increase & 95\% CI \\
\hline & \multicolumn{2}{c}{ Effect on cord blood-Hg } \\
\hline Cord blood-hemoglobin & 74.71 & 49.44 to 104.3 \\
Maternal blood-selenium & -5.66 & -23.4 to 16.14 \\
\hline & Effect on maternal blood-Hg \\
\hline Maternal blood-hemoglobin & 26.49 & 3.87 to 54.03 \\
Maternal blood-selenium & 15.75 & -8.12 to 45.82 \\
\hline
\end{tabular}




\section{Table 4}

Estimated factor loading $(\lambda)$ and error CV calculated for biomarkers of prenatal mercury exposure in a Faroese birth cohort by a structural equation model.

\begin{tabular}{|c|c|c|}
\hline Biomarker & Factor loading & Error CV \\
\hline \multicolumn{3}{|l|}{ Model 1} \\
\hline Cord blood-Hg & 1 & 0.105 \\
\hline Maternal blood-Hg & 0.858 & 0.323 \\
\hline Maternal hair-Hg & 0.981 & 0.420 \\
\hline \multicolumn{3}{|l|}{ Model $2^{*}$} \\
\hline Cord blood-Hg & 1 & 0.032 \\
\hline Maternal blood-Hg & 0.833 & 0.324 \\
\hline Maternal hair-Hg & 0.973 & 0.416 \\
\hline
\end{tabular}

